times more common in the group of icteric mothers, it must be emphasised that two perinatal deaths occurred in pregnancies associated with only maternal pruritus. Within the jaundiced group fetal outcome was not affected by the severity of the maternal biochemical disturbance or the gestational age at which symptoms began. In short, the individual fetus at risk is not identified by the indices currently used to gauge the severity of the maternal cholestasis.

The cause of these sudden intrauterine deaths is not known. The birthweights of both the surviving and stillborn infants were normally distributed for their various maturities. ${ }^{8}$ Hence probably, unlike the chronic nutritional deficiency seen in intrauterine growth retardation, impaired placental perfusion or transfer is not a feature of this disorder. The consistent neocropsy evidence of intrauterine fetal hypoxia and the high associated incidence of intrapartum asphyxia do, however, suggest that some form of metabolic disturbance may occur.

The reason for the increased rate of premature births is also unexplained. In pregnancies complicated by maternal cholestasis Laatikainen et al ${ }^{14}$ showed a change in fetal steroid synthesis. In particular, the fetus's liver has a reduced capacity to change 16- $\alpha$-hydroxylate dehydroepiandosterone (DHAS) into the major precursor of the inert metabolite, oestriol. As a result, increased amounts of DHAS may reach the placenta and thus be metabolised through an alternative steroid pathway to the active hormone, oestradiol. In view of the recent implication of rising maternal plasma oestradiol $17-\beta$ levels in the initiation of premature labour ${ }^{15}$, it is tempting to postulate that the impairment of 16- $\alpha$-hydroxylase activity in pregnancies affected by cholestasis produces an "oestradiol surge" and consequent premature delivery.

The increased incidence of postpartum haemorrhage in these women is more easily explained. The hepatic synthesis of coagulation factors II, VII, IX, and X requires adequate tissue levels of vitamin $\mathrm{K}$. As this is a fat soluble vitamin adequate absorption depends on the secretion of enough bile salts to promote mixedmicelle formation in the gut. Vitamin $\mathrm{K}$ deficiency may thus occur if maternal cholestasis is severe or prolonged. One of our patients was admitted from the antenatal clinic with generalised bruising together with greatly prolonged prothrombin and partial thromboplastin times. These values had been normal two weeks earlier and became so again within two days of parenteral vitamin $\mathrm{K}$ administration.

In view of the present inability to identify the individual fetus at risk of intrauterine death, we believe that pregnant women with cholestasis should be managed with watchful expectancy until 37 weeks' gestation. Then induction of labour should be considered. It seems desirable to conduct the pregnancy at a hospital fully equipped for intrapartum fetal monitoring and the intensive care of infants of low birth weight. In view of the possibility of a secondary disturbance in maternal coagulation we recommend the prophylactic administration of parenteral vitamin $\mathrm{K}$.

We thank Professor H O Lancaster for his statistical help, Professor R P Shearman for his review of this article, and the honorary medical staff at Royal Prince Alfred Hospital for allowing us to quote from their records.

Requests for reprints should be addressed to Dr B Storey, Department of Paediatrics, Royal Prince Alfred Hospital, Missenden Road, Camperdown, 2050, Australia.

\section{References}

1 Svanberg, A, Acta Obstetrica et Gynaecologica Scandinavica, 1954, 33, 434

2 Thorling, L, Acta Medica Scandinavica, 1955, 181, 83.

${ }^{3}$ Kater, R H M, and Mistilis, S P, Medical fournal of Australia, 1967, 1, 638.

4 Sherlock, S, Diseases of the Liver and Biliary System, p 296. Oxford, Blackwell, 1968.

${ }^{5}$ Barnes, C G, Medical Disorders in Obstetric Practice, p 160. Oxford, Blackwell, 1973.

${ }^{6}$ Mitchell, R G, and Farr, V, Clinics in Developmental Medicine, 1965 $19,83$.

${ }^{7}$ Morrison, J E, Foetal and Neonatal Pathology, p 169. London, Butterworth, 1970.

${ }^{8}$ Kitchen, W H, Australian Paediatric fournal, 1968, 4, 29.

9 Sutton, D H, Medical fournal of Australia, 1945, 1, 611.

10 Gruenwald, P, Biologica Neonatorum, 1963, 5, 215.

${ }^{11}$ Haemmerli, U P, in Diseases of the Liver, ed L Schiff, p 1036, Philadelphia and Toronto, Lippencott, 1969.

12 Davidson, C S, Fournal of Reproductive Medicine, 1973, 10, 107.

13 Rencoret, R, and Aste, H, Medical fournal of Australia, 1973, 1, 167.

14 Laatikainen, T J, Peltronen, J I, and Hylander, P L, fournal of Clinica Investigation, 1974, 53, 1709.

15 Tamby, R R L, Anderson, A B H, and Turnbull, A C, British Medical Fournal, 1974, 4, 67 .

\title{
Therapeutic experience with fludrocortisone in diabetic postural hypotension
}

\author{
I W CAMPBELL，D J EWING， B F CLARKE
}

British Medical fournal, 1976, 1, 872-874

\section{Summary}

Fourteen patients with diabetic postural hypotension were treated with fludrocortisone for a mean of 12 months (range 6-30 months). The mean daily dose of fludrocortisone was $0.2 \mathrm{mg}$ (range $0.1 \mathrm{mg}-0.4 \mathrm{mg}$ ). Standing systolic and diastolic blood pressures increased significantly $(P<0.001)$ after treatment with fludro-

Diabetic and Dietetic Department and University Department of Medicine, Royal Infirmary, Edinburgh EH3 9YW

I W CAMPBELL, MB, MRCP, senior registrar

D J EWING, MB, MRCP, lecturer

B F CLARKE, MB, FRCP, physician and senior lecturer in medicine cortisone and the postural hypotension decreased significantly $(P<0.001)$. Thirteen patients noted considerable symptomatic improvement. Fludrocortisone should be used cautiously in patients with congestive cardiac failure or the nephrotic syndrome.

\section{Introduction}

Postural hypotension is a prominent and disabling symptom of diabetic autonomic neuropathy. ${ }^{1}$ Although the use of fludrocortisone (9- $\alpha$-fluorohydrocortisone) is well known in the treatment of idiopathic postural hypotension, ${ }^{2}{ }^{3}$ its use has been only briefly mentioned in the management of diabetic postural hypotension. ${ }^{4-6}$ We have recently reported the acute changes produced by fludrocortisone in diabetics with postural hypotension ${ }^{7}$ and now report our clinical experience with this drug in the long-term treatment of this condition. 


\section{Patients and methods}

Fourteen diabetics (12 men and two women) with symptomatic postural hypotension (fall of systolic blood pressure of $30 \mathrm{~mm} \mathrm{Hg}$ or greater on changing from lying to standing) were treated with fludrocortisone as outpatients (see table). All but two were insulindependent; their mean age was 51 years (range 29-69 years); and the mean duration of diabetes mellitus was 20 years (range 4-35 years).

Lying and standing blood pressure values before and after fludrocortisone

Blood pressure $(\mathrm{mm} \mathrm{Hg})$

\begin{tabular}{|c|c|c|c|c|c|c|}
\hline \multirow{3}{*}{$\begin{array}{l}\text { Case } \\
\text { No }\end{array}$} & \multicolumn{4}{|c|}{ Blood pressure $(\mathrm{mm} \mathrm{Hg})$} & \multirow{3}{*}{$\begin{array}{l}\text { Final dose of } \\
\text { fludrocortisone } \\
\text { (mg/day) }\end{array}$} & \multirow{3}{*}{$\begin{array}{c}\text { Period of } \\
\text { treatment } \\
\text { (months) }\end{array}$} \\
\hline & \multicolumn{2}{|c|}{ Before fludrocortisone } & \multicolumn{2}{|c|}{ After fludrocortisone } & & \\
\hline & Lying & Standing & Lying & Standing & & \\
\hline 1 & $140 / 90$ & $8 5 \longdiv { 4 0 }$ & $180 / 100$ & $170 / 100$ & $0 \cdot 3^{*}$ & 12 \\
\hline 2 & $155 / 90$ & 7550 & $165 / 105$ & 13090 & $0 \cdot 2 *$ & 22 \\
\hline 3 & $140 / 80$ & 9060 & $160 / 90$ & $160 / 90$ & 0.3 & 18 \\
\hline 4 & $100 / 60$ & 7040 & $110 / 60$ & 10560 & $0 \cdot 2$ & 30 \\
\hline 5 & $90 / 60$ & 6030 & $100 / 70$ & 10570 & 0.4 & 15 \\
\hline 6 & $130 / 80$ & 8050 & $130 / 80$ & 10575 & 0.1 & 6 \\
\hline 7 & 13080 & 8050 & 13080 & $105 / 75$ & 0.3 & 6 \\
\hline 8 & 13070 & 10070 & $160 / 95$ & $145 / 95$ & 0.2 & 6 \\
\hline 9 & $140 / 90$ & 10580 & $155 / 70$ & $155 / 75$ & $0 \cdot 2$ & 6 \\
\hline 10 & $200 / 110$ & $150 / 100$ & 205110 & $180 / 100$ & $0.2 *$ & 9 \\
\hline & 11070 & 7050 & $130 / 90$ & $120 / 85$ & $0 \cdot 3$ & 12 \\
\hline & 17090 & 7050 & 15085 & 15085 & $0 \cdot 1$ & 6 \\
\hline 13 & $175 / 90$ & 13070 & $190 / 95$ & $180 / 90$ & $0 \cdot 2$ & 6 \\
\hline 14 & $180 / 105$ & $140 / 90$ & $140 / 100$ & $140 / 100$ & $0 \cdot 2^{*}$ & 9 \\
\hline
\end{tabular}

*Dose later reduced (see text).

Twelve patients had diabetic retinopathy (two background, six exudative, and four proliferative), and all had a blood urea of less than $6.6 \mathrm{mmol} / 1(40 \mathrm{mg} / 100 \mathrm{ml})$ before starting fludrocortisone. Of these 12 patients, five had proteinuria, four of whom (cases 1,2,10, and 14) had a reduced plasma albumin of less than $35 \mathrm{~g} / \mathrm{l}$. All but one patient had clinical evidence of peripheral neuropathy. In addition to the postural hypotension, one or more of the following features of autonomic neuropathy were present: impotence without loss of libido (all 12 men); intermittent diarrhoea (8 patients); symptoms of gastric atony (6); hypoglycaemic unawareness (5); gustatory sweating (2); and bladder paresis ( 1 ).

Before starting fludrocortisone five patients had been treated with full-length elastic tights without relief of postural hypotension and another patient was unsuccessfully treated with ephedrine hydrochloride tablets. Each patient was begun on $0.1 \mathrm{mg}$ fludrocortisone twice daily and this was adjusted for each patient for control both of the postural hypotension and avoidance of breathlessness and peripheral oedema (see table). Blood pressure was recorded by sphygmomanometry two hours after breakfast and the mean of three lying and standing values taken, at first every week and later every month once the dose of fludrocortisone was established. At each visit a blood sample was taken for determinating urea, electrolyte, and plasma protein concentrations. The mean length of follow-up was 12 months (range 6-30 months).

\section{Results}

The table shows the pre- and post-treatment lying and standing blood pressure values. The pretreatment values were the mean of at least six recordings taken on different occasions over several weeks. The post-treatment values were those at the end ot the treatment period except in four patients (cases 1, 2, 10, and 14), in whom the blood pressure recordings were those taken before the reduction of the fludrocortisone dosage (see below). There was no statistical difference in the lying blood pressure values before and after fludrocortisone treatment, but both standing systolic and diastolic blood pressures increased significantly $(P<0.001)$ after treatment with fludrocortisone, and, although blood pressure still fell slightly, the postural drop in both systolic and diastolic blood pressure was significantly reduced $(P<0.001)$. The effect of fludrocortisone on blood pressure was not related to the dose used. No patient developed severe hypertension and only two patients (cases 2 and 10) had a diastolic blood pressure exceeding $100 \mathrm{~mm} \mathrm{Hg}$ while on fludrocortisone.

Thirteen patients noticed a considerable improvement in their postural hypotensive symptoms, and the remaining patient (case 13) claimed only a little improvement despite good objective improvement in blood pressure. This patient also had cervical spondylosis and some of his dizziness may have been partly attributable to vertebrobasilar insufficiency.
The final mean daily dose of fludrocortisone was $0.2 \mathrm{mg}$ (range $0.1 \mathrm{mg}-0.4 \mathrm{mg}$ ). All four of the patients with initially reduced plasma albumin levels later developed the nephrotic syndrome and the fludrocortisone was reduced to prevent oedema. In three of these patients, all of whom have since died, fludrocortisone was subsequently stopped, and in the fourth patient (case 2 ) only a small dose $0.1 \mathrm{mg}$ every third day, was required. Serial blood analysis did not show any significant change in sodium or potassium values during treatment and except in the four patients with the nephrotic syndrome there were likewise no significant changes in the blood urea or plasma protein concentrations.

One patient (case 3) first developed symptoms of postural hypotension four weeks after treatment for pulmonary oedema complicating an acute myocardial infarction. She required no further diuretic treatment and has remained symptom-free on fludrocortisone. While on fludrocortisone treatment a second patient (case 11) developed pulmonary congestion and ankle oedema during pneumococal bronchopneumonia and on stopping the fludrocortisone temporarily there was no postural hypotension. Once the infection and pulmonary congestion were successfully treated the patient subsequently developed pronounced postural hypotensive symptoms and was restarted on fludrocortisone. A third patient (case 12) developed congestive cardiac failure secondary to ischaemic heart disease after six months on fludrocortisone and since then has required diuretic treatment; provided the patient has a trace of ankle oedema, she is free of symptoms of postural hypotension without fludrocortisone.

\section{Discussion}

Postural hypotension in diabetes usually results from a disturbance of the complex vascular reflex control of blood pressure, ${ }^{7}$ possibly with a decreased or absent renin secretion in response to the erect posture. ${ }^{8}$ It may be very distressing and in our experience the "symptomatic threshold" appears to be a fall in systolic blood pressure of $30 \mathrm{~mm} \mathrm{Hg}$ on standing up, although we know of two normotensive male diabetics with a fall of $70 \mathrm{~mm} \mathrm{Hg}$ associated with abnormal vascular reflexes but with no symptoms of faintness or dizziness. Patients need treating not only symptomatically to relieve faintness and dizziness but also because they may possibly die suddenly from brain stem anoxia. ${ }^{9}$

Various methods have been suggested for treating postural hypotension, including physical measures such as abdominal binders, antigravity suits, and elastic tights, all of which are cumbersome and inconvenient for the patient, especially if the postural hypotension is associated with diabetic diarrhoea. In one study ephedrine was less effective than fludrocortisone, ${ }^{3}$ and the latter is considered to be the best drug for treating postural hypotension irrespective of cause. ${ }^{10}$ In our previous study of diabetics with postural hypotension fludrocortisone produced a considerable decrease in the postural fall of systolic blood pressure, a decrease in orthostatic tachycardia, and an increase in total plasma volume with no significant change in the plasma or urine osmolality. ${ }^{\text {? }}$

More prolonged therapeutic experience with fludrocortisone confirms the blood pressure findings in our previous study. The mineralcorticoid activity of fludrocortisone seems to have been responsible for the therapeutic effect and although we originally thought that hypertension might complicate the longterm use of fludrocortisone this has not been so.

The mean daily dose of fludrocortisone $(0.2 \mathrm{mg})$ required for symptomatic relief is less than that required for controlling idiopathic postural hypotension, for which average doses are 0.5-2 mg/day..$^{30-12}$ This variation in dosage may be explained by the different site of the lesion in idiopathic (very often an afferent or central lesion) and diabetic postural hypotension. In the latter the lesion is most probably efferent, ${ }^{7}$ affecting sympathetic peripheral vasoconstrictor fibres, and fludrocortisone, in addition to its mineralcorticoid activity, may produce some constriction in partially denervated blood vessels. ${ }^{13}$

Although in our original study the fludrocortisone produced a rise in serum sodium and fall in serum potassium, ${ }^{7}$ these values remained within the normal range throughout the present longterm study. Proteinuria in a patient with postural hypotension 
should alert the clinician to use fludrocortisone with caution and the plasma albumin level should be carefully monitored-since any fall in the latter will potentiate the effect of the mineralocorticoid. The development of the nephrotic syndrome or of congestive cardiac failure, by producing fluid retention and secondary aldosteronism, has a "protective effect" in relieving the postural hypotension in autonomic neuropathy, although vascular reflexes such as the Valsalva manoeuvre and blood pressure response to sustained handgrip will still be abnormal. ${ }^{14}$ Fludrocortisone may therefore have to be balanced with a diuretic to avoid serious postural hypotension or excessive fluid retention. Provided fludrocortisone is used with caution in these conditions, it is most useful for treating diabetics with troublesome postural hypotension.

Request for reprints should be addressed to Dr I W Campbell.

\section{References}

${ }^{1}$ British Medical fournal, 1974, 3, 2.

${ }^{2}$ Hickler, R B, et al, New England fournal of Medicine, 1959, 261, 788.

${ }^{3}$ Bannister, R, Ardill, L, and Fentem, P, Quarterly fournal of Medicine, 1969, 38, 377.

4 Schatz, I J, Podolsky, S, and Frame, B, fournal of the American Medical Association, 1963, 186, 537

${ }^{5}$ Shear, L, Archives of Internal Medicine, 1968, 122, 467.

6 Finch, P J, Proceedings of the Royal Society of Medicine, 1971, 64, 803.

'Campbell, I W, Ewing, D J, and Clarke, B F, Diabetes, 1975, 24, 381.

${ }^{8}$ Christlieb, A R, Munichoodappa, C, and Braaken, J T, Diabetes, 1974, 23, 835 .

${ }^{9}$ Bannister, R, Lancet, 1971, 2, 175.

${ }^{10}$ British Medical fournal, 1970, 2, 247.

${ }^{11}$ Schirger, A, et al, fournal of the American Medical Association, 1962, 181, 822 .

${ }^{12}$ Frick, M H, Acta Medica Scandinavica, 1966, 179, 292.

${ }^{13}$ Schmid, P G, Eckstein, J W, and Abboud, F M, Circulation, 1966, 34, 620.

${ }^{14}$ Ewing, D J, et al, Lancet, 1973, 2, 1354.

\title{
Role of the kidney in regulating plasma immunoreactive beta-melanocyte-stimulating hormone
}

\author{
A G SMITH, SAM SHUSTER, A J THODY, F ALVAREZ-UDE, D N S KERR
}

British Medical fournal, 1976, 1, 874-876

\section{Summary}

An analysis of the factors that influence the increase in plasma immunoreactive $\beta$-melanocyte-stimulating hormone ( $\beta$-MSH) concentrations in chronic renal failure showed that: $(a)$ the increase correlated with the increase in serum creatinine concentrations; (b) $\beta$-MSH was not cleared from the plasma by haemodialysis; (c) $\beta$-MSH concentrations increased with length of time on dialysis and increased further after bilateral nephrectomy but there was no further increase with time; (d) $\beta$-MSH levels decreased to normal after renal transplantation; and $(e) \beta$-MSH was excreted in urine only when plasma levels rose to well above those of chronic renal failure (in Nelson's syndrome). These findings suggest that the kidney regulates plasma $\beta$-MSH by a non-excretory mechanism and is the major site of $\beta-M S H$ metabolism.

\section{Introduction}

We, ${ }^{1}$ and others, ${ }^{2}$ have recently found increased plasma concentrations of immunoreactive $\beta$-melanocyte-stimulating hormone $(\beta-\mathrm{MSH})$ in patients with chronic renal failure. By relating the changes in $\beta-\mathrm{MSH}$ levels to severity of renal failure and by studying the effect of various treatments on the plasma concentration of the hormone, we were able to find evidence for the mechanisms of this abnormality.

\footnotetext{
University Department of Dermatology, Newcastle upon Tyne NE1 4LP

A G SMITH, MB, MRCP, Wellcome research fellow

SAM SHUSTER, PHD, FRCP, professor of dermatology

A J THODY, PHD, lecturer

University Department of Medicine, Newcastle upon Tyne NE1 4LP F ALVAREZ-UDE, LMS, research registrar

D N S KERR, MSC, FRCP, professor of medicine
}

\section{Patients and methods}

Forty-five patients with chronic renal failure (CRF) were studied. Fourteen patients were treated conservatively (group 1) and others with more advanced CRF were treated as follows: 15 patients who had not undergone nephrectomy were on haemodialysis (group 2); eight patients who had undergone bilateral nephrectomy were on haemodialysis (group 3); and eight patients who had undergone renal transplantation from two to 31 months previously and in whom the serum creatinine was below $177 \mu \mathrm{mol} / 1(2 \mathrm{mg} / 100 \mathrm{ml})$ were taking prednisone $10-40 \mathrm{mg} /$ day and azathioprine $150 \mathrm{mg} /$ day (group 4).

Blood was taken from each patient (immediately before dialysis in those so treated) and plasma immunoreactive $\beta$-MSH was measured by a modification of the method of Thody and Plummer. ${ }^{3}$ In one patient blood was taken on two occasions from the arterial line at the start of haemodialysis, from the aterial and venous lines after three hours of dialysis, and from the arterial line at the end of dialysis. On the first occasion an Ultraflo 2 coil with Cuprophan was used and on the second a Rhone Poulenc RP6 dialyser with high permeability acronytrile membrane linked to a closed circuit monitor. In a second patient blood was taken before haemodialysis (using the Ultraflo 2 coil), during dialysis, and after dialysis.

Urinary immunoreactive $\beta$-MSH was measured in one normal subject and in four patients with Nelson's syndrome. A $100-\mathrm{ml}$ sample of freshly passed urine was first concentrated by freeze drying. The residue was dissolved in $10 \mathrm{ml}$ of diluent buffer, which was acidified to $\mathrm{pH} 4$ and the $\beta-\mathrm{MSH}$ extracted by adsorption on to the silicate Spherosil, The $\beta-M S H$ was eluted from the Spherosil by a solution of equal parts of ammonia and ethanol; this solution was evaporated off and the $\beta-\mathrm{MSH}$ assayed as for the plasma. With this method the recovery of added synthetic human $\beta-M S H$ to $100 \mathrm{ml}$ urine was up to $40 \%$.

\section{Results}

In patients with chronic renal failure not yet requiring treatment by dialysis there was a correlation between the degree of renal impairment as measured by serum creatinine levels and the plasma levels of $\beta-\mathrm{MSH}$ (fig 1).

Of the patients maintained on haemodialysis those who had undergone bilateral nephrectomy had significantly higher levels of $\beta-M S H$ than those who had not (fig 2). The mean value $( \pm S E$ ) for patients with kidneys was $249 \pm 46 \mathrm{ng} / \mathrm{l}$, which was significantly less than the mean value of $558 \pm 69 \mathrm{ng} / \mathrm{l}$ after nephrectomy $(\mathrm{P}<0.001)$. This difference did not relate to the duration of dialysis, as the mean 